\title{
Computational fluid dynamics simulation of wind-driven inter-unit dispersion around multi-storey buildings: Upstream building effect
}

Ai, Zhengtao; Mak, C.M.; Dai, Y.W.

Published in:

Indoor and Built Environment

Link to article, DOI:

$10.1177 / 1420326 \times 17745943$

Publication date:

2019

Document Version

Peer reviewed version

Link back to DTU Orbit

Citation (APA):

Ai, Z., Mak, C. M., \& Dai, Y. W. (2019). Computational fluid dynamics simulation of wind-driven inter-unit

dispersion around multi-storey buildings: Upstream building effect. Indoor and Built Environment, 28(2), 217-234. https://doi.org/10.1177/1420326X17745943

\section{General rights}

Copyright and moral rights for the publications made accessible in the public portal are retained by the authors and/or other copyright owners and it is a condition of accessing publications that users recognise and abide by the legal requirements associated with these rights.

- Users may download and print one copy of any publication from the public portal for the purpose of private study or research.

- You may not further distribute the material or use it for any profit-making activity or commercial gain

- You may freely distribute the URL identifying the publication in the public portal 


\title{
CFD simulation of wind-driven inter-
}

\section{unit dispersion around multi-story}

\section{buildings: upstream building effect}

\author{
Y.W. Dai ${ }^{a}$, C.M. Mak ${ }^{\mathrm{a}}$, Z.T. Ai ${ }^{\mathrm{b}}$ \\ a Department of Building Services Engineering, The Hong Kong Polytechnic \\ University, Hong Kong, China \\ ${ }^{\mathrm{b}}$ International Center for Indoor Environment and Energy, Department of Civil \\ Engineering, Technical University of Denmark
}

*Corresponding author: C. M. Mak, Department of Building Services Engineering, The Hong Kong Polytechnic University, Hung Hom, Kowloon, Hong Kong. Email: cheukming.mak@polyu.edu.hk

\section{Abstract}

Previous studies on inter-unit dispersion around multi-story buildings focused mostly on an isolated building. Considering that the presence of upstream building(s) would significantly modify the airflow pattern around a downstream building, this study intends to investigate the influence of such changed airflow patterns on inter-unit dispersion characteristics around a multi-story building due to wind effect. CFD method in the framework of Reynolds-averaged Navier-stokes modeling is employed to predict 
the coupled outdoor and indoor airflow field, while the tracer gas technique is adopted to simulate the dispersion of infectious agents between units. Based on the predicted concentration field, a mass conservation based parameter, namely re-entry ratio, is further used to evaluate quantitatively the inter-unit dispersion possibilities and thus assess risks along different routes. The presence of upstream building(s) destroys the strong impingement of approaching flows but brings a more complex and irregular airflow pattern around the downstream multistory buildings, which then lead to a more scattered distribution of re-entry ratio values among different units and uncertain dispersion routes. These findings imply that the inter-unit transmission patterns are subject to surrounding buildings. A building accompanied by several buildings ordinarily in an urban environment reveals the importance of the present study.

\section{Keywords}

CFD, inter-unit dispersion, $\mathrm{ACH}$, natural ventilation, infectious risk assessment

\section{Introduction}

Natural ventilation through windows is a convenient and sustainable ventilation strategy to induce air exchange to cool the overheated indoor air and dilute the contaminated air in residential buildings (1-3). However, apart from bringing fresh air from outside, this approach also causes disagreeable consequences that the outdoor pollutants make their 
incursion into the interior area (4), which include traffic exhaust, dust, and pollen (5), as well as airborne transmitted virus, such as severe acute respiratory syndrome (SARS) (6). It has been proved that cross transmission between units (so-called inter-unit dispersion) is a valid airborne transmission route of infectious diseases (6-8). Thus, understanding the mechanisms and routes of cross transmission grows essentially significant in operating dispersion and ventilation control approach.

A substantial body of former researches conducted on the airflow field and pollutant dispersions around buildings have built foundation for the present study. Onsite measurements, wind tunnel experiments and numerical simulations have been carried out regarding to the inter-unit dispersion. Li et al.(6, 8) identified the inter-unit dispersion as an important airborne transmission route after the outbreak of SARS epidemic in 2003 in Amoy Gardens housing by CFD method and multi-zone modelling. Then, Niu and Tung (9) adopted on-site tracer gas technique to conduct the pollutant transportation path through windows which is primary buoyancy effect under singleside ventilation. They found that the re-entry ratio of gaseous pollutant from a lower unit to an immediate upper unit can reach up to $7 \%$, which is equivalent to about $2 \%$ infectious risk based on the Wells-Riley infection risk assessment model (7). But this work was limited to two upper-lower floors. Liu et al. $(10,11)$ and Wang et al. (12) performed wind tunnel experiments to investigate the wind effect on the pollutant dispersion around cross shape (\#) buildings. It was found that the pollutant could travel 
along both upward and downward direction to re-enter into units, as well as horizontal dispersion. However, only a specific geometry of the building was investigated in their research. More recently, a wind tunnel experiment with a generic shape multi-story building was carried out by $\mathrm{Mu}$ et al. $(13,14)$ to research the inter-unit pollutant transmission with tracer gas method, examining the effect of wind direction and source location. The re-entry pollutant concentration was calculated under assumed circumstances to assess the infection probability of each unit. However, these two wind tunnel experiment studies were both limited to an isolated building. Further, the wind tunnel tests may not be able to consider the indoor airflow field correctly due to the similarity problem.

Some recent researches (15-17) have shown that CFD approach is specifically suitable for investigation of natural ventilation and becomes the most widely used model presently. Gao et al and Liu et al $(18,19)$ investigated the CFD simulations of an on-site measurement (9) to quantify the infection risks. Ai et al. (20-23) studied the inter-unit dispersion characteristics of gaseous pollutant in and around two hypothetical envelope buildings under wind-induced single-side ventilation by CFD method. The tracer gas transmission mechanism on the windward and leeward sides was presented and compared with that of cross shape (\#) buildings. The results showed that inter-unit dispersion pattern was highly dependent on the wind direction and the re-entry ratio of gaseous pollutant can reach up to $10 \%$. But these previous studies were limited to an 
isolated building with slab-like shape. Recently, Cui et al. (24) numerically calculated the inter-unit re-entry ratios of a cylinder shape building under the influence of an upstream interfering building. The results showed that the presence of an upstream building changed the airflow characteristics and pollutant transportation routes dramatically. However, the work by Cui et al. (24) considered only a single upstream building and a limited number of source locations on the windward side of the target building.

One of the main purposes of natural ventilation in residential buildings is to dilute air pollutant in order to improve the indoor air quality. Many studies have been conducted to reveal the natural airflow patterns. However, most former researches on the natural ventilation and pollutant dispersion are limited to an isolated building or a specific shape of building, which cannot be used for better prediction in actual urban environment. Therefore, the present work aims to investigate airflow characteristics and pollutant dispersion in a more realistic situation of urban environment.

The present study focuses on the inter-unit dispersion characteristics of gaseous pollutants within a cylinder-like multi-story building under the effect of two upstream buildings based on computational fluid dynamics. The upstream buildings with generic shape are set to better analyze the real urban environment. The two upstream buildings and the target building are intended to represent a basic building group in an actual 
urban environment, which serves to provide the basic airflow fields for the investigation of inter-unit dispersion. It has been reported that the buoyancy-driven pollutant transmission, investigated in previous studies $(9,18)$, is unidirectional, namely upward, and only important in relatively low wind speed conditions (lower than $0.9 \mathrm{~m} / \mathrm{s}$ ). Therefore, this present study only considers the wind-driven pollutant dispersion, which is much more diverse in terms of dispersion routes and re-entry ratios. Given that the airflow pattern and pollutant dispersion around buildings should be significantly affected when occurring different prevailing wind directions, the approaching wind angle is considered as one of the key factors in the research. Tracer gas technique, carbon dioxide $\left(\mathrm{CO}_{2}\right)$, is adopted to simulate the gaseous pollutant in the present study, owing to the similarity of its aerodynamics characteristics to those of various gaseous pollutants and fine particles. The results from this research are expected to be useful in understanding the pollutant dispersion mechanism in urban environment and in developing effective strategies in control of infectious respiratory diseases.

\section{CFD methods and model validation}

\section{Turbulence models}

The CFD approach has been commonly used to predict airflow patterns and pollutant dispersions in and around buildings. The two-equation Reynolds-averaged Navier- 
Strokes (RANS) models with standard $k-\varepsilon$ turbulence model (25) and its modifications $(26,27)$ maintain the most widely used turbulence model to solve wind engineering and atmospheric dispersion problems (28). Turbulence effects in this study are taken into consideration by using renormalization group (RNG) $k-\varepsilon$ model (29), and the enhanced wall function is applied to model the airflow in the near-wall regions. For incompressible flow, the time-averaged governing equations can be written generally as:

$\frac{\partial}{\partial t}(\varphi)+\nabla \cdot\left(\bar{u}_{\varphi}\right)=\nabla \cdot\left(\Gamma_{\varphi} \nabla_{\varphi}\right)+S_{\varphi}$

where $\varphi$ represents the scalars: the velocity ingredients $u(\mathrm{~m} / \mathrm{s}), v(\mathrm{~m} / \mathrm{s}), w(\mathrm{~m} / \mathrm{s})$, the turbulent kinetic energy $k\left(\mathrm{~m}^{2} / \mathrm{s}^{2}\right)$, its dissipation rate $\varepsilon\left(\mathrm{m}^{2} / \mathrm{s}^{3}\right)$, and the mass fraction $M_{i}\left(\mathrm{~g} / \mathrm{m}^{3}\right)$; term $\bar{u}(\mathrm{~m} / \mathrm{s})$ the mean velocity, $\Gamma_{\varphi}$ the effective diffusion coefficient for each variate, and $S_{\varphi}$ the source term.

The RNG $k-\varepsilon$ model offers a number of improvements over the standard $k-\varepsilon$ model, which presents an authentic interrelation between the turbulence transport and Reynolds number by a more precise differential equation. This allows the RNG model to have superior performance in predicting the low-Reynolds-number and near-wall flows. Further, an additional strain-dependent term, $R_{\varepsilon}$, in the transport equation for $\varepsilon$ makes the RNG model with high sensitivity over dealing with rapid strain and 
streamline curvature than the standard $k-\varepsilon$ model. The added term $R_{\varepsilon}$ is shown by the equation as:

$R_{\varepsilon}=\frac{C_{\mu} \rho \eta^{3}\left(1-\eta / \eta_{0}\right)}{1+\xi \eta^{3}} \cdot \frac{\varepsilon^{2}}{k}$

where $C_{\mu}, \eta_{0}$ and $\xi$ are model constants, and $\eta \equiv S k / \varepsilon$ where $S$ is the scale of strain rate. A more detailed demonstration of the RNG model and its empirical values is offered in Fluent (2010).

The governing equations of numerical models are discretized into algebraic equations on a staggered grid system with the finite volume method.

\section{Description of the wind tunnel experiment}

In the present study, a wind tunnel experiment conducted in the University of Hamburg (30) is used to validate the RANS models and near wall functions. Airflow and dispersions around a finite array of rectangular building models (CEDVAL B1-1) were measured at a reduced scale of 1:200 in the Blasius wind tunnel. The experiment model included $3 \times 7$ array of buildings with four facing pollutant sources located on the leeward side of one target building, the physical configuration of which is shown in Fig. 1. The high quality experiments were conducted with the boundary layer flow which 
have been validated by full-scale data in the test section before the building model was set up. Some locations on five planes were measured in the experiment: four vertical planes at $Y=-H, Y=-0.6 H, Y=-0.4 H$, and $Y=0$, respectively, and a horizontal plane at $Z=0.5 H$. The Laser Droppler Velocimetry (LVD) technique was adopted to perform the velocity and turbulence fields, and the Flame Ionization Detector (FID) was used to measure the concentration of the pollutant. Noted that $k$ is calculated by the measured fluctuating velocities, $k=0.5\left(u^{\prime 2}+v^{\prime 2}+w^{\prime 2}\right)$. The concentration field is presented in a non-dimensional form as:

$K_{c}=\frac{C_{\text {local }}}{C_{\text {source }}} \cdot \frac{U_{\text {ref }} H^{2}}{Q_{\text {source }}}$

where $C_{\text {local }}$ is the measured tracer gas concentration (ppm) with environment background concentration subtracted, $C_{\text {source }}$ is the tracer gas concentration (ppm) at the source, $U_{r e f}$ is the reference wind speed $(\mathrm{m} / \mathrm{s})$ measured at the height of $0.66 \mathrm{~m}, \mathrm{H}$ is the model building height $(H=0.125 m)$ and $Q_{\text {source }}$ is the total source strength $\left(m^{3} / s\right)$ 


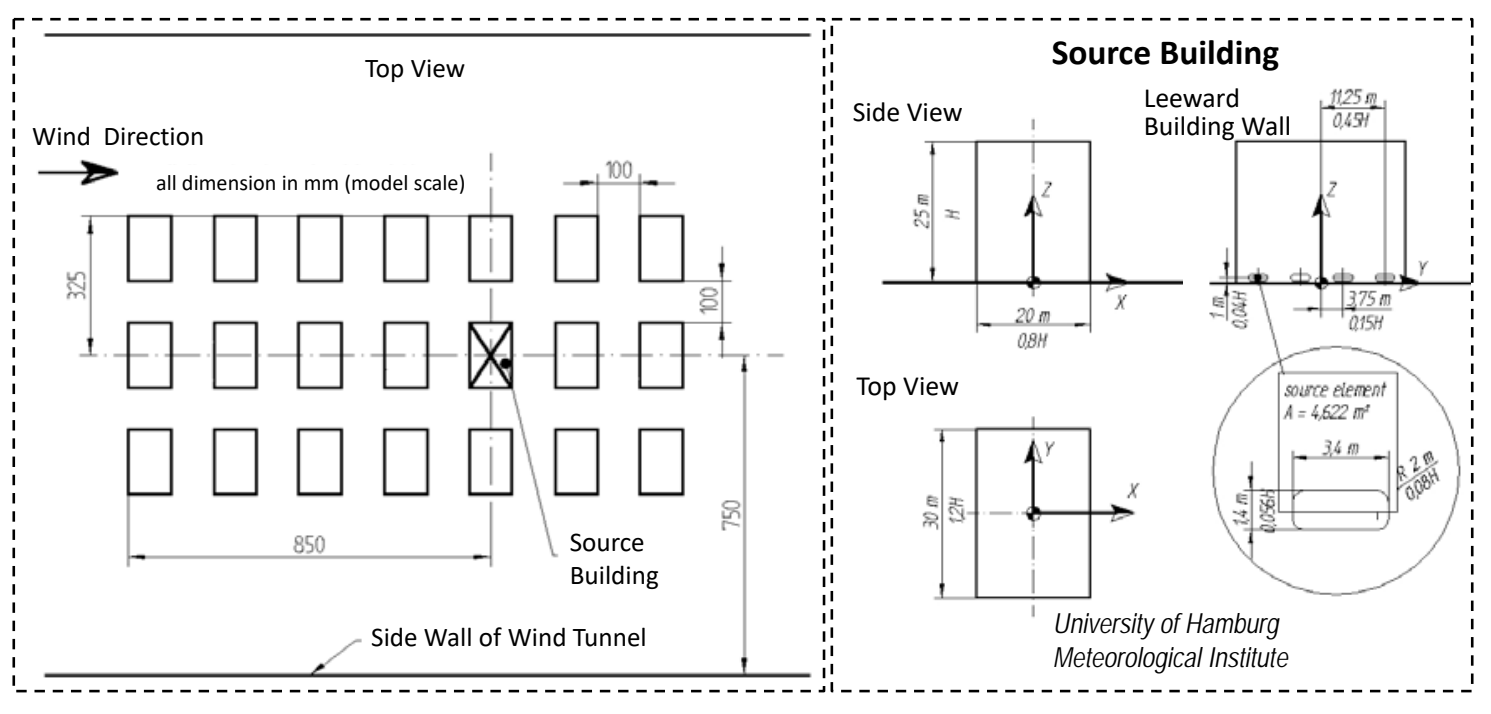

Fig. 1 Dimensions of building models, the source building and source emissions in wind tunnel experiment (30).

\section{Computational settings and parameters}

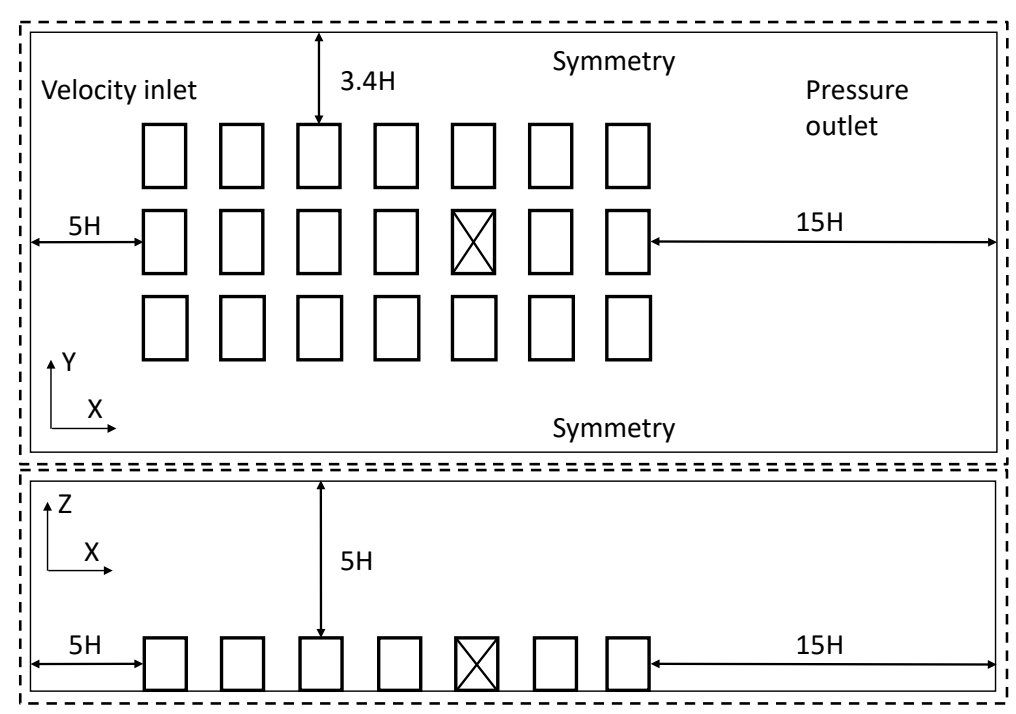


Fig. 2 Computational domain: top view and side view.

A computational domain shown in Fig. 2 is constructed to simulate the flow and dispersion fields around the building models. This domain size based on the existing best practice guideline is spatially large enough to eschew the intervention within the flow development, except for the side width which is built upon the wind tunnel width. The boundary conditions at the domain's inlet, lateral sides, celling and outlet are summarized in Table 1, where the inlet velocity profile follows a power law, by fitting $U=U_{H} \cdot\left(\frac{Z}{Z_{H}}\right)^{\alpha}, U_{H}=6 \mathrm{~m} / \mathrm{s}, Z_{H}=0.5 \mathrm{~m}$ and $\alpha=0.21$. In addition, the Von Karman constant $\kappa$ is 0.4187 and $C_{\mu}=0.069(31,32)$. When the dispersion is simulated, the tracer gas $\left(\mathrm{CO}_{2}\right)$ is uniformly released from the four source elements (see Fig. 1) with a constant velocity of $0.025 \mathrm{~m} / \mathrm{s}$ in the $\mathrm{X}$ direction.

Table 1

Boundary conditions 


\begin{tabular}{lc}
\hline & Power law type \\
\hline Domain inlet & $U=U_{H}\left(\frac{Z}{Z_{H}}\right)^{0.21}$ \\
& $k=0.5\left(u^{\prime 2}+v^{\prime 2}+w^{\prime 2}\right)$ \\
& $\varepsilon=C_{\mu}{ }^{0.75} k^{1.5} / l$
\end{tabular}

A comprehensive mesh test is conducted for the dependence of numerical solutions on grid number. Three mesh systems with approximately 5.4, 6.0 and 6.7 million grids of structured hexahedra cells are created and compared (see Fig. 3(a)), in which the medium one is selected because of the compromise between numerical accuracy and cost. The standard wall function and enhanced wall functions were both considered. For these two scenarios, the minimum grids widths near the domain ground and building walls were $0.005 \mathrm{~m}\left(y^{+} \approx 35\right)$ and $0.0002 \mathrm{~m}\left(y^{+}<5\right)$, resectively. A schematic view of the mesh information can be found in Fig. 3(b). Because of the improved resolution of the near-wall regions and a better treatment of the near-wall flows, the enhanced wall functions provide more accurate velocity fields near the domain ground and in the region around the building roof when compared to that given by standard wall functions (33). 


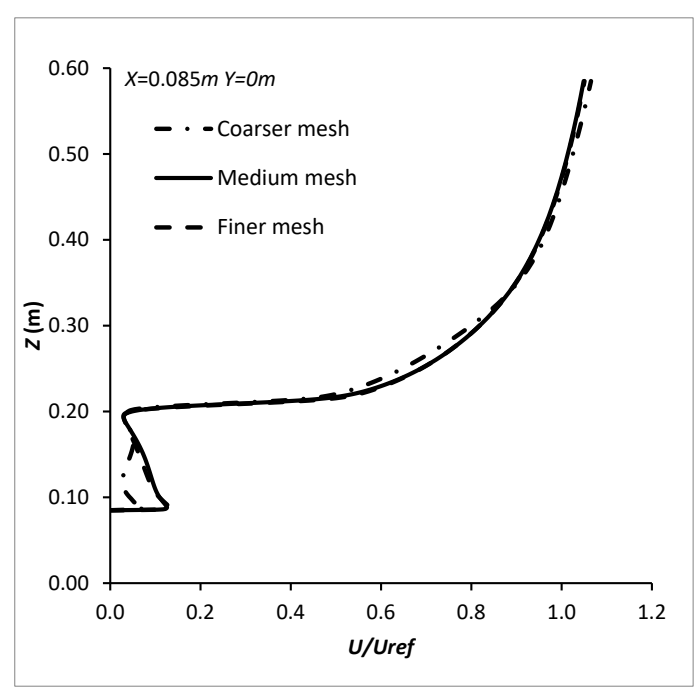

Fig. 3 Comparison of mean velocity profiles using three types of mesh systems at the vertical line of $X=0.085 m$.
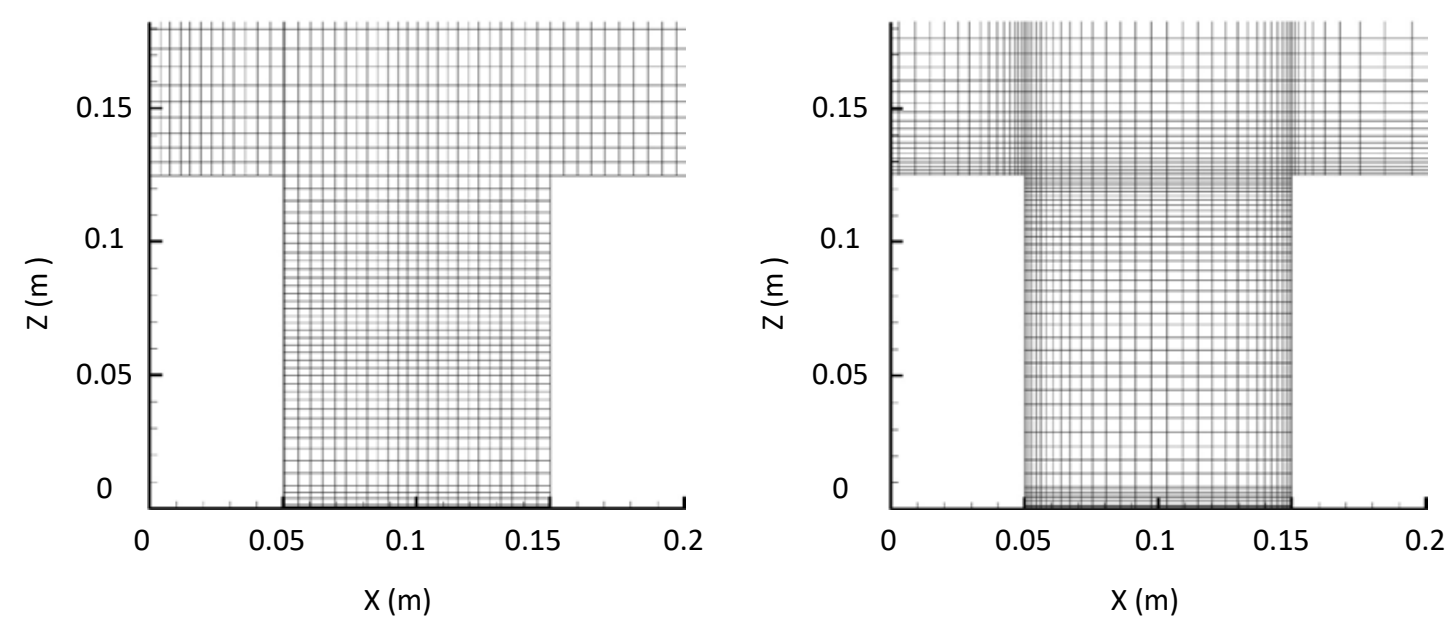

Fig. 3(b) Mesh details for a part of the vertical line of $Y=0$ : the coarser for standard wall functions and the finer for the enhanced wall functions. 
Commercial CFD code ANSYS Fluent 13.0.0 (34) is used to simulate the wind tunnel model. Four numerical setting combinations are conducted in the validation work, standard $k-\varepsilon$ model plus standard wall functions; standard $k-\varepsilon$ model plus enhanced wall functions; RNG $k-\varepsilon$ model plus standard wall functions and RNG $k-$ $\varepsilon$ model plus enhanced wall functions, respectively. The SIMPLEC algorithm is adopted for the pressure-velocity coupling, the pressure interpolation is second order accuracy discretization schemes, as well as both the convection and diffusion terms. Convergence is supposed to be achieved when all the scalar residuals reached $10^{-6}$ and the stability of calculation is attained over packs of iterations.

\section{Comparison between experimental and simulated results}

The comparison of non-dimensional air velocity distribution of $\mathrm{X}$ direction along six vertical lines between the numerical results and wind tunnel data is shown in Fig. 4. Compared to the experiment data, the average deviations of the velocities produced by these four numerical combinations are $24.85 \%, 20.75 \%, 16.31 \%$ and $8.48 \%$, respectively. Obviously, the RNG $k-\varepsilon$ model with enhanced wall function produced more accurate airflow results around the target body, except for the slightly larger velocities above the roof of target building model $(Z>0.15 \mathrm{~m})$. However, this little deficiency can be accepted because the airflow distribution over the building roof $(Z>$ $0.15 \mathrm{~m}$ ) is not under the consideration of present study. 

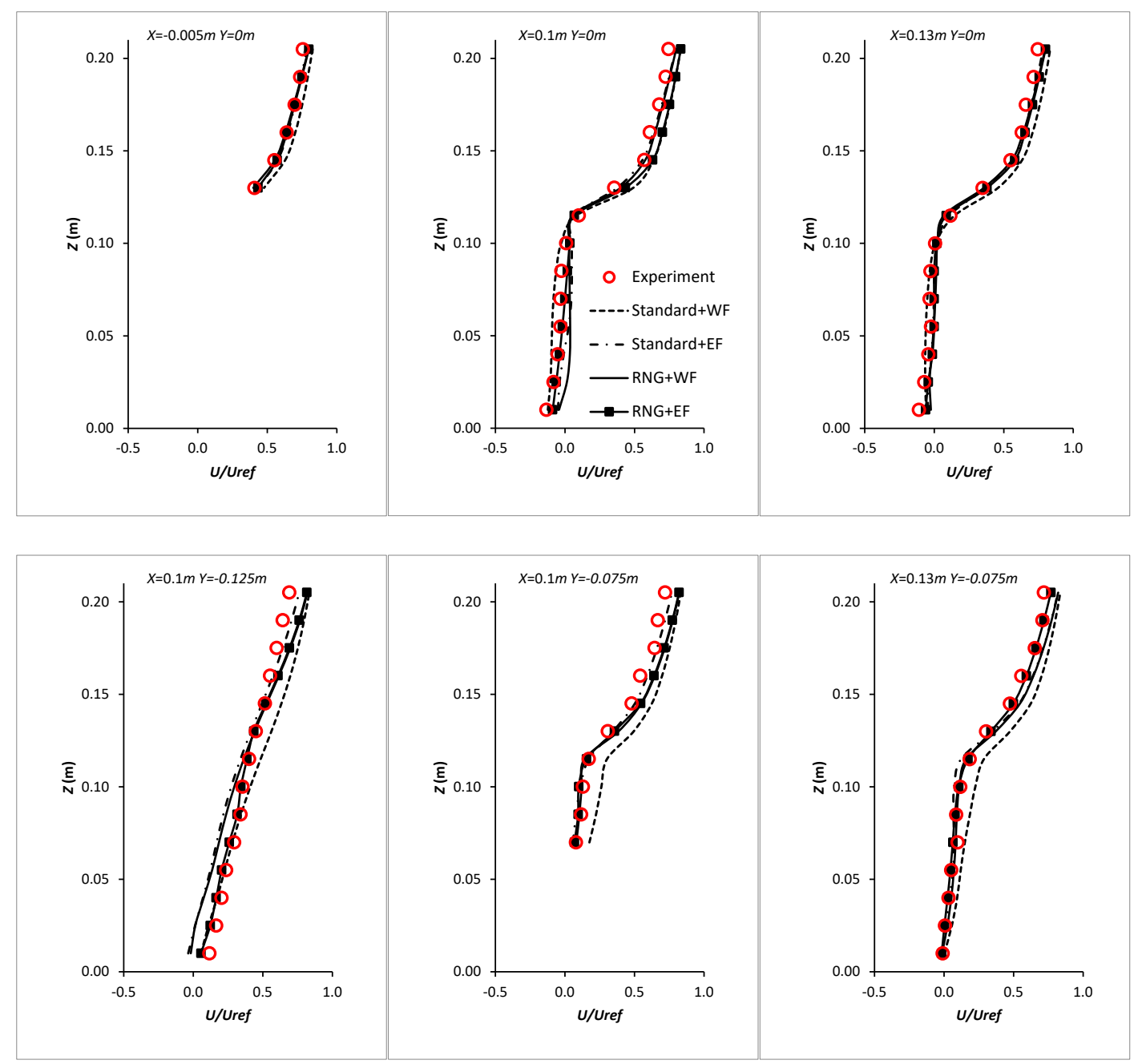

Fig. $4 \mathrm{X}$ velocity distribution at the six vertical lines: Standard + WF indicates standard $k-\varepsilon$ model plus standard wall functions; Standard + EF indicates standard $k-\varepsilon$ model plus enhanced wall functions; renormalization group (RNG) + WF indicates RNG $k-\varepsilon$ model plus standard wall functions; RNG + EF indicates RNG $k-\varepsilon$ model plus enhanced wall functions. 
Based on the RNG $k-\varepsilon$ model and enhanced wall function, the air pollutants are released to predict the concentration field. The turbulent Schmidt number $\left(S c_{t}\right)$, which is defined as the ratio of turbulent momentum diffusivity to concentration (tracer gas) diffusivity, performs an essential influence on the calculation of concentration equation in the simulation with RANS models (35). The specific value of $S c_{t}$ has a significant effect depended on dispersion problems and flow structures and the optimum values of this number are distributed in the range of $0.2-1.3(35,36)$. In the present study, the value of 0.7 is used and it shows good agreement of concentration field between numerical simulation data and wind tunnel results. The non-dimensional concentrations of tracer gas $K_{c}$ at the measured positions are shown in Fig. 5.

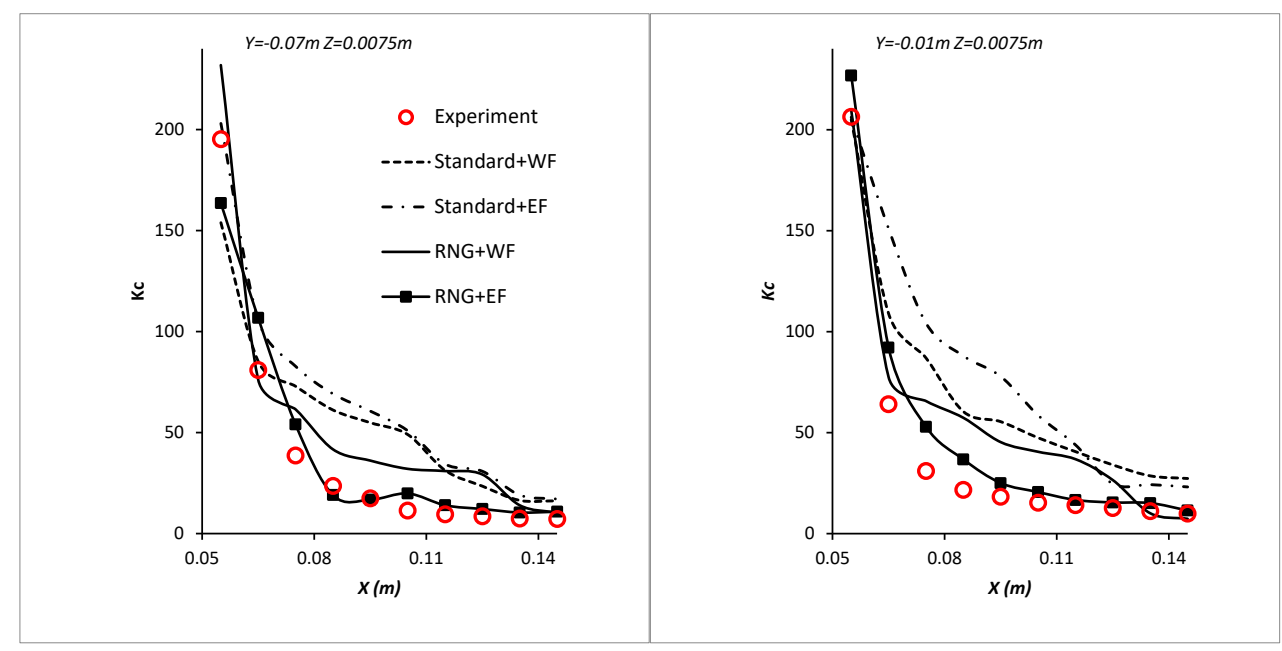

Fig. 5 Tracer gas concentration at two horizontal lines: Standard + WF indicates standard $k-\varepsilon$ model plus standard wall functions; Standard + EF indicates standard $k-\varepsilon$ model plus enhanced wall functions; renormalization group (RNG) $+\mathrm{WF}$ 
indicates RNG $k-\varepsilon$ model plus standard wall functions; RNG + EF indicates RNG $k-\varepsilon$ model plus enhanced wall functions.

Overall, this validation justifies the adoption of the selected numerical models (RNG $k-\varepsilon$ model and enhanced wall functions) in the later simulations of the airflow distribution and inter-unit dispersion field around the target building.

\section{Configuration descriptions}

In order to investigate the effect of upstream buildings on the wind-induced inter-unit dispersion around a multi-story building in urban environment, a 1:20 reduced scale (37) downstream building and two upstream interfering buildings are adopted. The building dimensions in the work of Cui et al (24) are used in this present work. Two rectangular models without openings are employed as upstream interfering buildings, shown in Fig. 6(a). The target building has two independent units on each story with opposite window opening directions, shown in Fig. 6(b). The unit dimensions are: width $\left(D_{X}\right) \times$ length $\left(D_{Y}\right) \times$ height $\left(D_{Z}\right)=6 m \times 3 m \times 3 m$, and the window: width $\left(D_{X}\right)$ $\times$ height $\left(D_{Z}\right)=1 \mathrm{~m} \times 2 \mathrm{~m}$, in the prototype. The window bottom is $1 \mathrm{~m}$ above the each story. The target building has 4 stories, the dimension of which is width $\left(D_{X}\right) \times$ length $\left(D_{Y}\right) \times$ height $\left(D_{Z}\right)=6 m \times 6 m \times 12 m$. With the juxtaposition of the two upstream buildings, the distances of the three buildings are equal to the width of the building, the 
arrangement is shown in Fig. 7(a). The upstream building in front of the target building is named as Building A, and the other is Building B. The distance between two building models is smaller than the leeward recirculation length (24).

In order to reproduce the original full-scale flow, a series of similarity criteria including geometry similarity, boundary layer flow similarity and Reynolds independence are needed to be achieved. The computational domain for all the cases is depended on the best practice guidelines (38), shown in Fig. 7(a), an upstream distance of $5 D_{Z}$, downstream distance of $15 D_{Z}$, lateral distance of $6 D_{Z}$ and height of $6 D_{Z}$ are chosen to simulate the natural ventilation, which is large enough to achieve the accurate airflow distribution. The Reynolds number $\operatorname{Re}\left(\operatorname{Re}=V_{r e f} \cdot D_{z} / v\right)$ at the top of the building roof in the present study is 40,000 and is much larger than the recommended value, a threshold of 15,000 (39), which means the Reynolds independence is fulfilled.
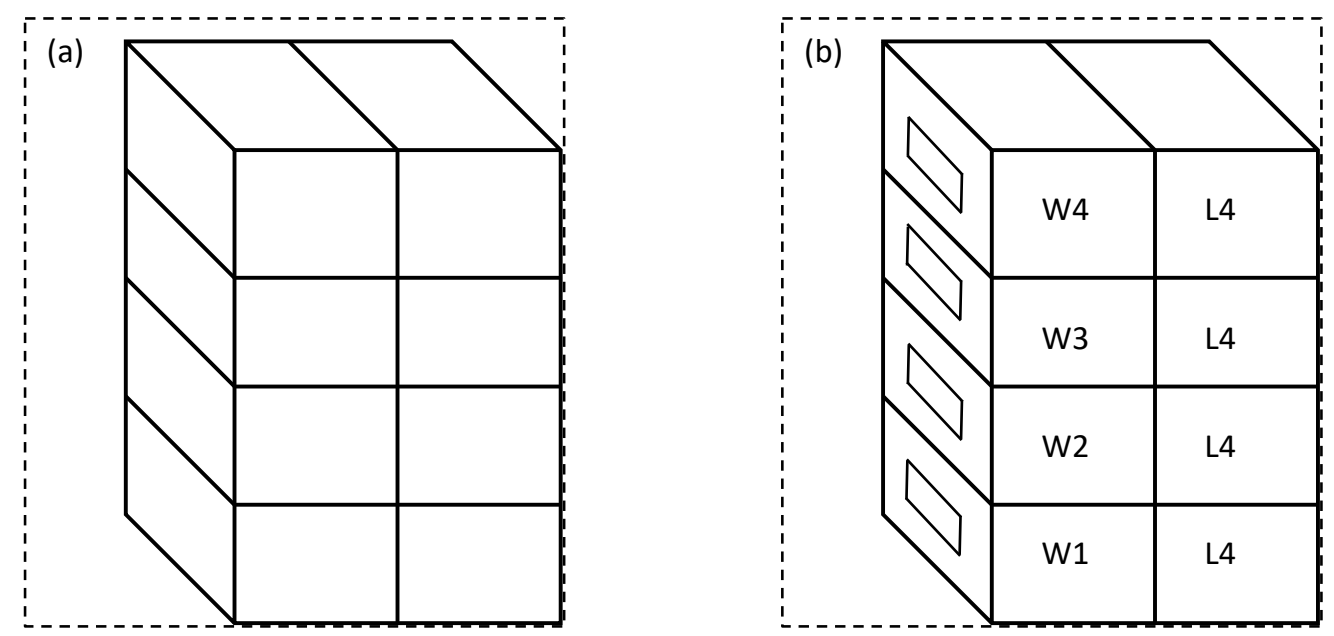
Fig. 6 (a) physical model of upstream buildings; (b) physical model of the target building.
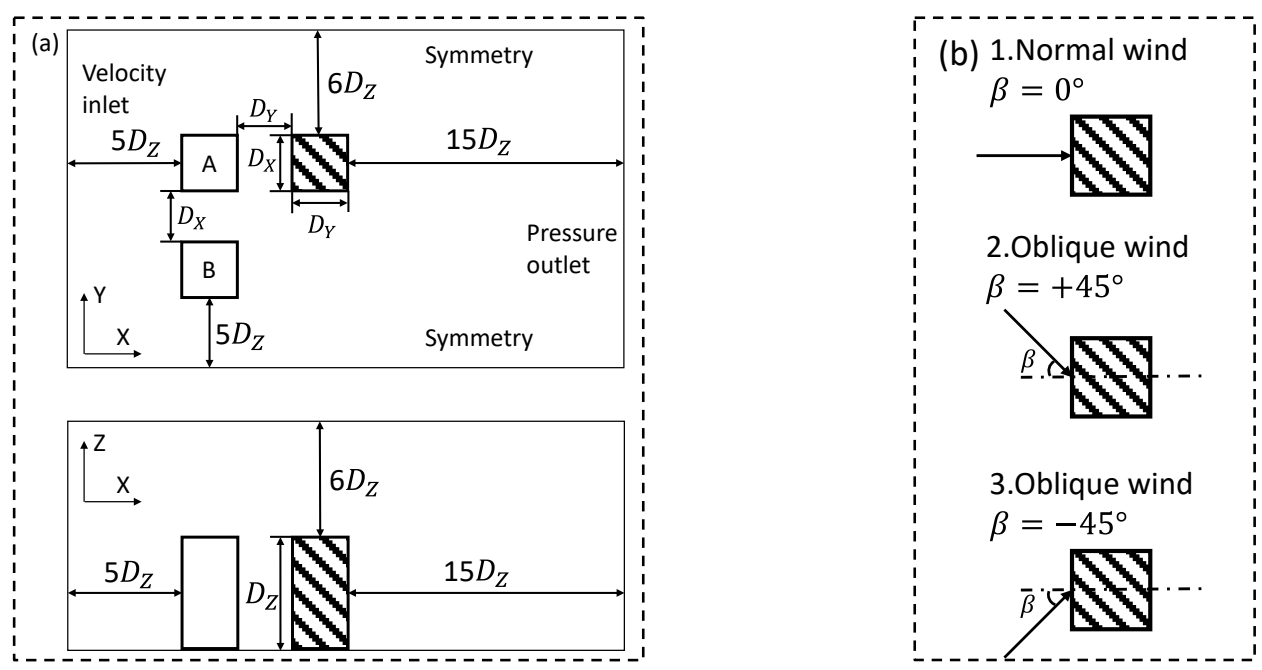

Fig. 7 (a) the arrangement and computational domain of three buildings; (b) three wind directions.

The present study selects three wind directions, shown in Fig. 7(b); $\beta$ is the angle between the incident wind direction and perpendicular to the building surface. The wind at the inlet of computational domain in an urban environment follows a power law profile by the following equations:

$V_{z}=V_{\text {ref }}\left(\frac{Z}{Z_{H}}\right)^{\alpha}=1.14 V_{\text {ref }} Z^{0.25}$ 
where $Z_{H}$ is the building height $\left(Z_{H}=0.6 m\right), V_{r e f}$ is the wind velocity at the height of building roof $\left(V_{\text {ref }}=4 \mathrm{~m} / \mathrm{s}\right)$. The turbulence at the inlet boundary is characterized by turbulent intensity and length scale, which are $8 \%$ and $1 \mathrm{~m}$, respectively. A mesh with 6.0 million grids is employed after a mesh sensitivity test similar to which was described in the validation section. Air exchange rate $(\mathrm{ACH})$ of each unit is calculated by an integral method:

$A C H=3600 \times \frac{0.5 \int_{0}^{A}\left|V_{x}\right| d A}{V o l_{R}}$

where $V_{x}(\mathrm{~m} / \mathrm{s})$ is the velocity component normal to the plane of the openings, $A\left(\mathrm{~m}^{2}\right)$ the area of the window, and $\mathrm{Vol}_{R}\left(\mathrm{~m}^{3}\right)$ the volume of each unit. The tracer gas $\mathrm{CO}_{2}$ was released at a rate of $8 \mathrm{mg} / \mathrm{s}$ in the middle of each unit at the height of $1.6 \mathrm{~m}$. Some researchers $(9,21)$ adopted the re-entry ratio $\left(R_{k}\right)$ to evaluate the inter-unit pollutant dispersion. The re-entry ratio is defined as the fraction of exhaust air from a source unit $i$ which re-enters into another unit $j$. It can be calculated by the following equation:

$$
R_{k}=M_{i-j} \frac{\operatorname{Vol}_{j}(A C H)_{j}}{\operatorname{Vol}_{i}(A C H)_{i}}
$$


where $M_{i-j}$ is mass fraction of concentration that originates from the source unit $i\left(C_{i}, \mathrm{~kg} / \mathrm{m}^{3}\right)$ and is present in another unit $j\left(C_{j}, \mathrm{~kg} / \mathrm{m}^{3}\right)$, which can be calculated

as $M_{i-j}=\frac{C_{j}}{C_{i}}$. The concentration in a unit is calculated based on the breathing plane (the standing position) at the height of $1.6 \mathrm{~m}$ above the floor. $(A C H)_{i}$ is the air exchange rate of the source unit and $(A C H)_{j}$ is the air exchange rate of the re-entry unit.

The unit are named as shown in Fig. 6(b), in which W indicates the windward side, L the leeward side, and numbers first to fourth story.

\section{Results and discussion}

\section{Airflow characteristics}

The airflow distribution in and around a building is essential to affect the airborne transmission of pollutant between units. For an isolated building encountered by urban wind, the wind will deflect over the top, down in front and around the sides. Because of the air pushing against the building, much of the windward wall will get relatively high pressure and the peak pressure will occur at about 2/3 of the height of the building, where is the stagnation zone (the upstream building in Fig. 8(a) is under this situation). When influenced by a single upstream building (24), air mainly flows downward near the windward side of the downstream building, causing a recirculation zone near the top 
of the leeward side of the upstream building, shown in Fig. 8(a). Comparing to a single upstream building, the circumstance under two upstream buildings is different. Fig. 8(b) shows the streamlines and mean velocity on the vertical center plane $(Y=0)$ of buildings under normal wind direction $\left(\beta=0^{\circ}\right)$. Influenced by two upstream buildings, air flows downward near the windward side of the downstream building and causes a small recirculation zone closing to the ground. The downward flow and recirculation in the near-wall flow implies that the presence of upstream buildings have considerable effect on the inter-unit dispersion routes, which may cause pollutants released from the ground floor cannot be transported upper ward. Further, under the effect of two upstream buildings, the near-wall flow on the windward side of the target building has changed, which induces more low-speed areas.

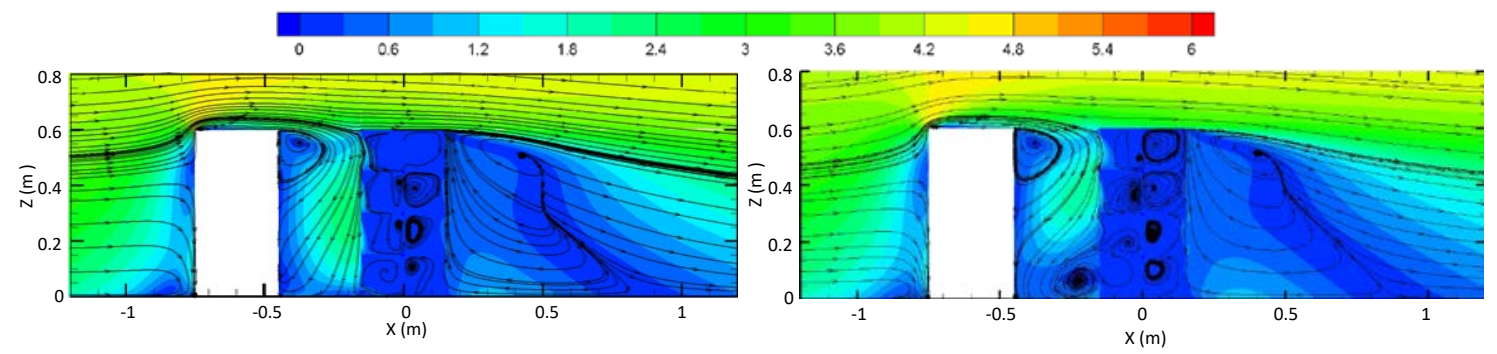

(a) a single upstream building

(b) two upstream buildings

Fig. 8 (a) streamlines and mean velocity on the vertical center plane of a single upstream buildings $\left(\beta=0^{\circ}\right.$ ); (b) streamlines and mean velocity on the vertical center plane of two upstream buildings $\left(\beta=0^{\circ}\right)$. 
Under the wind direction of $+45^{\circ}\left(\beta=+45^{\circ}\right)$, Fig. 9(a) shows the streamlines and mean velocity on the vertical center plane of the target building. In general, the flow pattern in the windward side is mainly consisted of primarily upward wind and vertical wind , as well as small vortices, while the leeward side is characterized by a strong upward airflow and a small reattachment on the top of the roof, which remains similar to the basic flow pattern under the situation of an isolated building (21). However, the airflow distribution under the wind direction of $-45^{\circ}\left(\beta=-45^{\circ}\right)$, as shown in Fig. 9(b), is dissimilar and characterized by the combination of several strong vortices in the windward side and a substantially upward airflow in the leeward of the target building. When the wind is oblique, the airflow fields are drastically changed because of the upstream buildings, inducing a large high-speed zone in the near-wall area, which implies that the ventilation of the target building is more effective and pollutants disperse more easily under this situation.

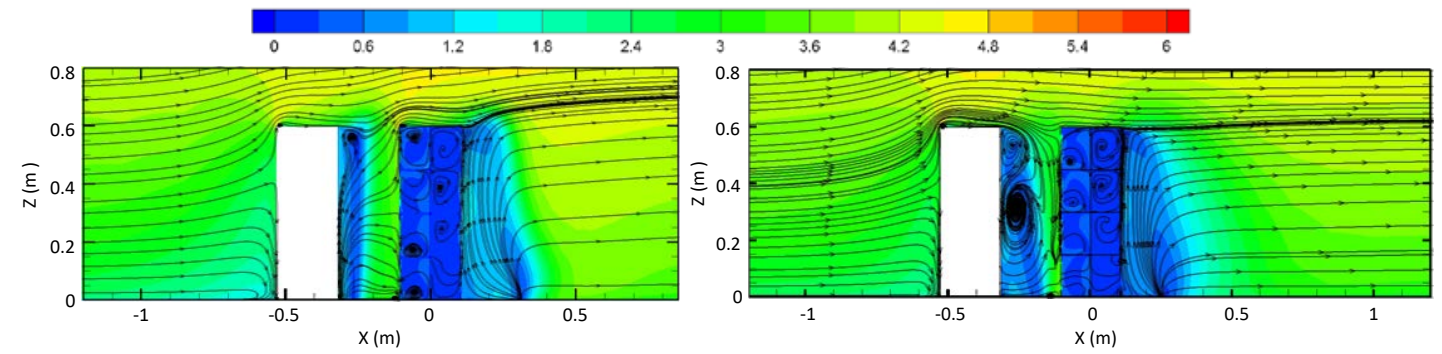

(a) vertical center plane under $\beta=+45^{\circ}$

(b) vertical center plane under $\beta=-45^{\circ}$ Fig. 9 Streamlines and mean velocity on the vertical center plane of the target building under oblique wind directions. 
Fig. 10(a) shows the airflow path lines on the horizontal plane at the breathing level on the third story of the target building $(Z=0.37 \mathrm{~m})$ with two upstream buildings. In general, for an isolated building, air flows separately into lateral sides under normal wind direction $\left(\beta=0^{\circ}\right)$, causing pollutants released from windward unit be diluted quickly (20). For a single upstream building (24), two recirculation zones appear on the windward side of the target building, shown in Fig. 11(a), which is similar to the present study. As mentioned above, a small vortex occurs near the ground on the windward side of target building, which indicates that airflow field may present differently in the lower area. Fig. 10(b) shows the airflow streamlines and mean velocity field on the horizontal plane at the middle of ground floor $(Z=0.08 \mathrm{~m})$, comparing to a single upstream building shown in Fig. 11(b), a recirculation zone is formed on the windward side of the target building because of the existence of upstream building $\mathrm{B}$. The airflow field near the target building is changed due to the asymmetry arrangement of the building group, which leads to larger wind speed near the lateral side and diverse pollutant transported routes. 


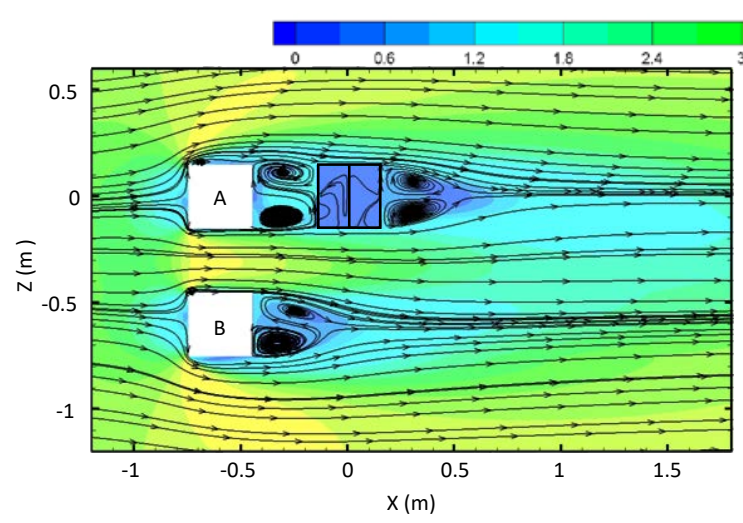

(a) $\beta=0^{\circ} Z=0.37 \mathrm{~m}$

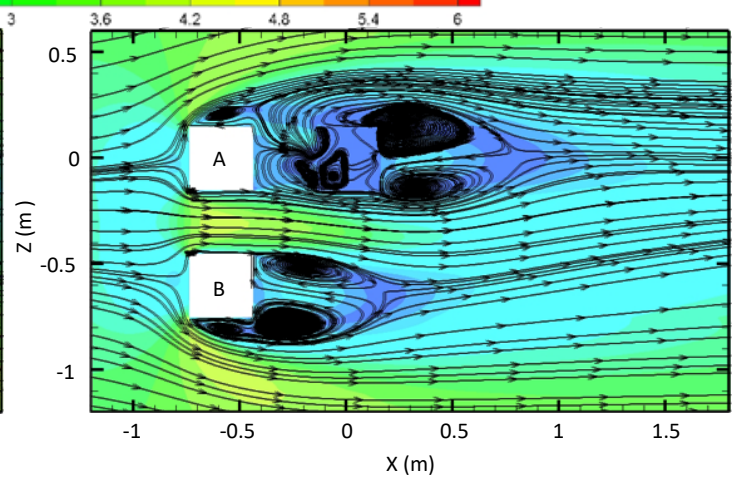

(b) $\beta=0^{\circ} Z=0.08 \mathrm{~m}$

Fig. 10 Streamlines and mean velocity on horizontal planes of the target building under different heights with two upstream buildings.

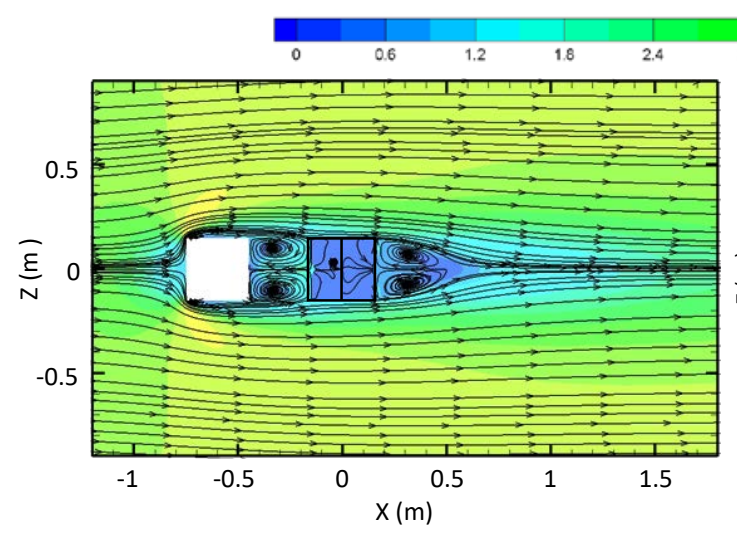

(a) $\beta=0^{\circ} Z=0.37 \mathrm{~m}$

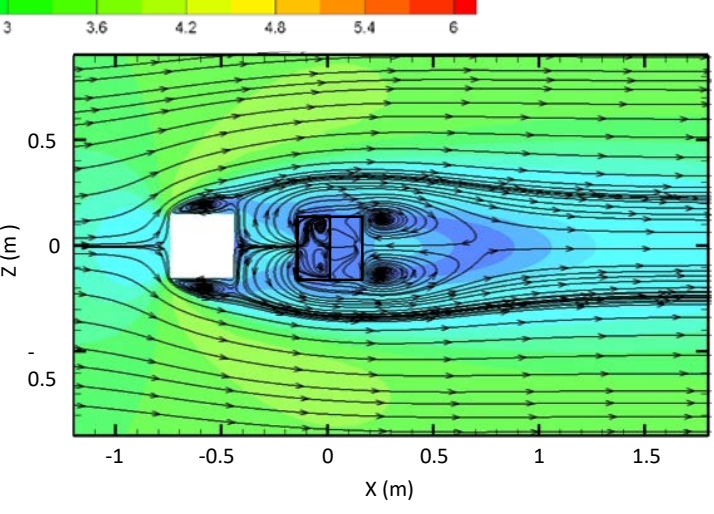

(b) $\beta=0^{\circ} Z=0.08 \mathrm{~m}$

Fig. 11 Streamlines and mean velocity on horizontal planes of the target building under different heights with a single upstream building. 


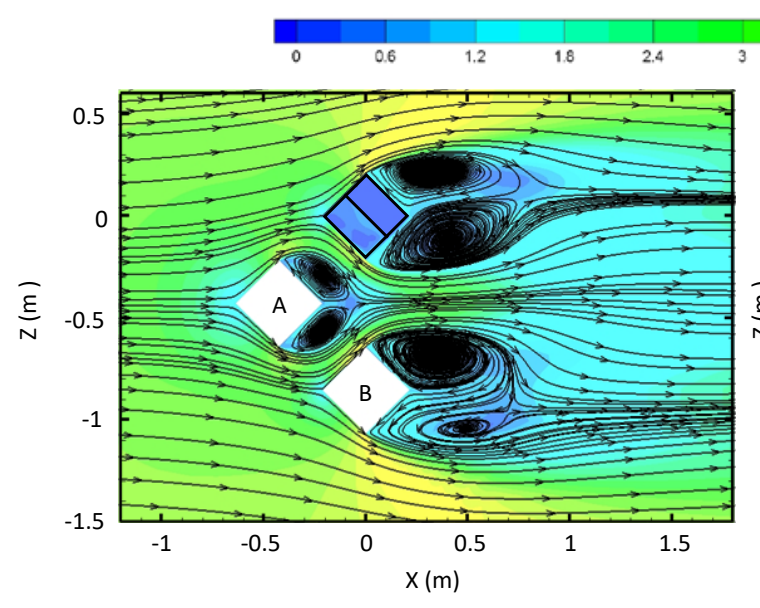

(a) $\beta=+45^{\circ} Z=0.37 \mathrm{~m}$

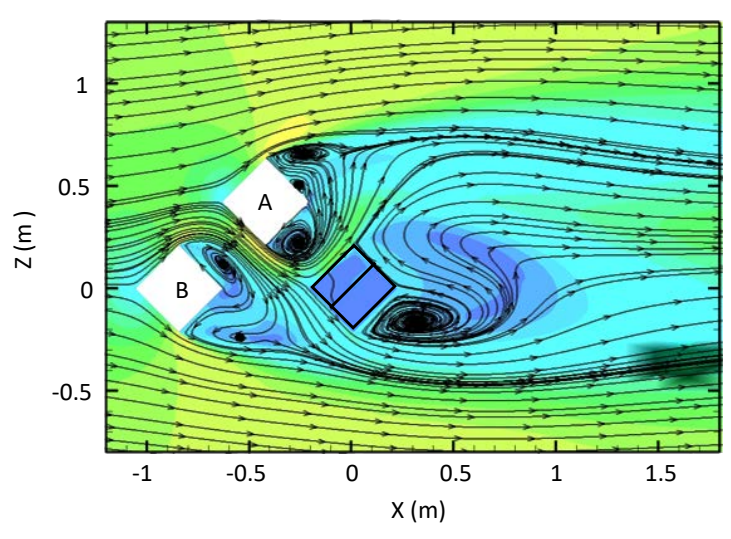

(b) $\beta=-45^{\circ} Z=0.37 \mathrm{~m}$

Fig. 12 Streamlines and mean velocity on horizontal planes of the target building with oblique wind directions.

When the wind direction is oblique, the air flow patterns are significantly different. Fig. 12(a) shows the airflow streamlines under the wind direction of $+45^{\circ}$ $\left(\beta=+45^{\circ}\right)$. There are two windward and two leeward walls on each building, when the wind approaches, it first meets the sharp corners and then flows around the leeward side rapidly, which maintains the basic pattern on the building surfaces as that under the normal incident wind (40). On the leeward side, the pressure difference leads to two low-pressure recirculation zones. With such flow pattern, the pollutant released from the windward units is quickly and effectively diluted into the flow stream while the two recirculation zones may induce that to re-enter into leeward units. The other wind direction $\left(\beta=-45^{\circ}\right.$ ), as shown in Fig. 12(b), with disparate airflow field, displays recirculation zones on both windward and leeward side of the target building, which 
means more pollutant transportations may be brought on because of the two upstream interfering buildings.

\section{Ventilation}

Table 2 shows the ACH values for each unit under three wind directions. W represents a unit on windward side while $\mathrm{L}$ on the leeward side. When the wind direction is in normal incidence, the presence of upstream interfering buildings significantly improve the ACH values of windward side units, comparing to an isolated building (21). However, notices should be brought to unit W1 and W2 when comparing the ACH values of the present study to that of a single upstream building (W1 is 11.15 and W2 is 4.36) (24), ACH value of unit W1 reduces about $115 \%$, which indicates that, with one more upstream interfering building (Building B), contaminants in unit W1 has less chance to be transported outside from window. But in unit W2, the ACH value increases about $44 \%$, this can be explained by the small vertex on the windward side of the target building which appears abreast unit W1. This near-wall wind fluctuation drives indoor and outdoor air exchange in W2 but blocks in W1. On the leeward side, a negative effect can be noticed on ACH values comparing to that of an isolated building.

Table $2 \mathrm{ACH}$ values of each unit under three wind directions. 


\begin{tabular}{cccc}
\hline $\mathrm{ACH}\left(h^{-1}\right)$ & $\beta=0$ & \multicolumn{2}{c}{$\beta=+45^{\circ} \beta=-45^{\circ}$} \\
\hline W4 & 23.00 & 107.34 & 85.86 \\
W3 & 4.92 & 107.55 & 90.47 \\
W2 & 7.73 & 101.71 & 94.38 \\
W1 & 5.19 & 93.16 & 101.28 \\
L4 & 0.96 & 2.98 & 3.59 \\
L3 & 0.94 & 13.88 & 11.37 \\
L2 & 3.67 & 20.64 & 16.15 \\
L1 & 4.06 & 20.05 & 14.48 \\
\hline
\end{tabular}

When the wind directions are oblique $\left(\beta=+45 \&-45^{\circ}\right)$, the $\mathrm{ACH}$ values of all units are considerably larger than under normal incidence wind direction $\left(\beta=0^{\circ}\right.$ ). However, in both oblique wind directions, the unit L4 shows extremely low ACH value in comparison with other units. This may be caused by the low pressure area on the leeward side of the target building which forms a relative low-speed zone adjacent to unit L4. The low air exchange rate of L4 may induce the concentration of air pollutant into the room.

From the present simulation results, it is obvious that the location of unit has essential impact on the characteristics of airflow. With the existence of two upstream interfering buildings, the interactions between indoor and outdoor airflow pattern will be redistributed, causing diverse wind directions and routes of pollutant transmission.

\section{The dispersion and re-entry tracer gas}


Pollutants generated from one unit may re-enter into another unit of a multi-story building under wind-induced natural ventilation in urban environment. Especially for a densely populated city, like Hong Kong, most residential buildings are high-rise cylinder-like buildings, which leads to a high risk of pollutant transportations among units of windward and leeward sides. The pollutant transmission patterns are discussed in this section. Table 3 presents the re-entry ratio $R_{k}$ of tracer gas from a source to other units under different wind directions, $R_{k}$ equals $100 \%$ means the unit is the source location area (with a box in the table). The re-entry ratios equal or larger than $0.10 \%$ are highlighted. Elaborations of each case are presented below.

Table 3 Re-entry ratios $R_{k}$ of each unit with diverse source locations under three wind directions. 


\begin{tabular}{|c|c|c|c|c|c|c|c|}
\hline$R_{k}$ & $\beta=0$ & $\beta=+45^{\circ}$ & $\beta=-45^{\circ}$ & $R_{k}$ & $\beta=0$ & $\beta=+45^{\circ}$ & $\beta=-45^{\circ}$ \\
\hline W4 & $100.00 \%$ & $100.00 \%$ & $100.00 \%$ & W4 & $0.00 \%$ & $0.00 \%$ & $0.00 \%$ \\
\hline W3 & $1.46 \%$ & $0.00 \%$ & $0.02 \%$ & W3 & $0.00 \%$ & $0.00 \%$ & $0.00 \%$ \\
\hline W2 & $0.49 \%$ & $0.00 \%$ & $0.01 \%$ & W2 & $0.00 \%$ & $0.00 \%$ & $0.00 \%$ \\
\hline W1 & $0.24 \%$ & $0.00 \%$ & $0.01 \%$ & W1 & $0.00 \%$ & $0.00 \%$ & $0.00 \%$ \\
\hline L4 & $0.00 \%$ & $0.00 \%$ & $0.00 \%$ & $\mathrm{~L} 4$ & $100.00 \%$ & $100.00 \%$ & $100.00 \%$ \\
\hline L3 & $0.00 \%$ & $0.01 \%$ & $0.02 \%$ & L3 & $0.01 \%$ & $0.16 \%$ & $0.06 \%$ \\
\hline L2 & $0.02 \%$ & $0.01 \%$ & $0.03 \%$ & L2 & $0.01 \%$ & $0.22 \%$ & $0.07 \%$ \\
\hline L1 & $0.02 \%$ & $0.01 \%$ & $0.03 \%$ & L1 & $0.01 \%$ & $0.20 \%$ & $0.06 \%$ \\
\hline W4 & $0.01 \%$ & $0.00 \%$ & $0.00 \%$ & W4 & $0.00 \%$ & $0.00 \%$ & $0.00 \%$ \\
\hline W3 & $100.00 \%$ & $100.00 \%$ & $100.00 \%$ & W3 & $0.00 \%$ & $0.00 \%$ & $0.00 \%$ \\
\hline W2 & $9.74 \%$ & $0.00 \%$ & $0.02 \%$ & W2 & $0.00 \%$ & $0.00 \%$ & $0.00 \%$ \\
\hline W1 & $1.61 \%$ & $0.00 \%$ & $0.02 \%$ & W1 & $0.00 \%$ & $0.00 \%$ & $0.00 \%$ \\
\hline L4 & $0.01 \%$ & $0.00 \%$ & $0.00 \%$ & L4 & $3.17 \%$ & $0.79 \%$ & $0.72 \%$ \\
\hline L3 & $0.01 \%$ & $0.01 \%$ & $0.01 \%$ & L3 & $100.00 \%$ & $100.00 \%$ & $100.00 \%$ \\
\hline L2 & $0.06 \%$ & $0.02 \%$ & $0.01 \%$ & $\mathrm{~L} 2$ & $0.09 \%$ & $0.04 \%$ & $0.03 \%$ \\
\hline L1 & $0.07 \%$ & $0.02 \%$ & $0.01 \%$ & L1 & $0.05 \%$ & $0.03 \%$ & $0.02 \%$ \\
\hline W4 & $0.00 \%$ & $0.00 \%$ & $0.00 \%$ & W4 & $0.00 \%$ & $0.00 \%$ & $0.00 \%$ \\
\hline W3 & $0.00 \%$ & $0.00 \%$ & $0.01 \%$ & w3 & $0.00 \%$ & $0.00 \%$ & $0.00 \%$ \\
\hline W2 & $100.00 \%$ & $100.00 \%$ & $100.00 \%$ & W2 & $0.00 \%$ & $0.00 \%$ & $0.00 \%$ \\
\hline W1 & $2.27 \%$ & $0.00 \%$ & $0.06 \%$ & W1 & $0.00 \%$ & $0.00 \%$ & $0.00 \%$ \\
\hline L4 & $0.01 \%$ & $0.00 \%$ & $0.00 \%$ & L4 & $0.30 \%$ & $0.15 \%$ & $0.12 \%$ \\
\hline L3 & $0.01 \%$ & $0.02 \%$ & $0.01 \%$ & L3 & $0.79 \%$ & $2.76 \%$ & $1.79 \%$ \\
\hline L2 & $0.04 \%$ & $0.03 \%$ & $0.01 \%$ & $\mathrm{~L} 2$ & $100.00 \%$ & $100.00 \%$ & $100.00 \%$ \\
\hline L1 & $0.05 \%$ & $0.03 \%$ & $0.01 \%$ & $\mathrm{~L} 1$ & $0.07 \%$ & $0.03 \%$ & $0.02 \%$ \\
\hline W4 & $0.00 \%$ & $0.00 \%$ & $0.00 \%$ & W4 & $0.00 \%$ & $0.00 \%$ & $0.00 \%$ \\
\hline W3 & $0.00 \%$ & $0.00 \%$ & $0.01 \%$ & w3 & $0.00 \%$ & $0.00 \%$ & $0.00 \%$ \\
\hline W2 & $0.12 \%$ & $0.00 \%$ & $0.04 \%$ & W2 & $0.00 \%$ & $0.00 \%$ & $0.00 \%$ \\
\hline W1 & $100.00 \%$ & $100.00 \%$ & $100.00 \%$ & W1 & $0.00 \%$ & $0.00 \%$ & $0.00 \%$ \\
\hline L4 & $0.01 \%$ & $0.00 \%$ & $0.00 \%$ & L4 & $0.11 \%$ & $0.03 \%$ & $0.02 \%$ \\
\hline L3 & $0.01 \%$ & $0.02 \%$ & $0.01 \%$ & L3 & $0.17 \%$ & $0.19 \%$ & $0.07 \%$ \\
\hline L2 & $0.05 \%$ & $0.03 \%$ & $0.01 \%$ & L2 & $2.11 \%$ & $1.44 \%$ & $0.46 \%$ \\
\hline L1 & $0.05 \%$ & $0.04 \%$ & $0.01 \%$ & L1 & $100.00 \%$ & $100.00 \%$ & $100.00 \%$ \\
\hline
\end{tabular}

\section{Under normal wind direction $\left(\beta=0^{\circ}\right)$}

On the windward side, the exhaust air from the units re-enters into the leeward units

with negligible ratios $(<0.1 \%)$. This basically demonstrates the gaseous pollutants

generated from windward side, driven by the recirculation flows and large wind velocity 
on lateral side, directly disperse downstream. From the summary of re-entry ratios, more detailed observations can be made.

Firstly, when the gaseous pollutant is located in the unit W1, which is nearby the recirculation zone, $R_{k}$ of most units are negligible, except for the minute value to W2 $(0.12 \%)$. Obviously, the momentum of the downward flow is partially transferred to the frontal recirculation and partially to the lateral separations, shown as Fig. 8(b), which blocks the pollutant cross transmission.

Secondly, when the source is located in the unit W2, pollutants are mainly transported along the airflow to the unit below, shown in Fig. 8(b), due to the high pressure difference between the unit W2 area and the vortex below. The most affected unit is W1, which has the $R_{k}$ value of $2.27 \%$. This value is a significant reduction to that under circumstance of a single upstream building, which is $15.16 \%$ in Cui's work. The result implies that, the presence of Building B decreases $R_{k}$ for unit W1, while also decreases $R_{k}$ of leeward units in the target building. This is because the vertical and horizontal recirculation zones reduce the pollutant transmission, which results from the increment of wind velocity in lateral side of target building. The diluted efficiency of gaseous contamination is amplified due to the presence of Building B.

Thirdly, when the pollutant is released from unit W3, the units below are both affected, especially for unit W2, $R_{k}$ is up to $9.74 \%$. Owing to the recirculation vortex 
behind the roof of Building A, the pollutants released from the unit W3 are transported downward predominantly. Comparing to the circumstance of a single upstream building, a relative low air velocity area formed near the unit W2, which causes the pollutants released from unit W3 to re-enter into W2 massively, larger than $6.76 \%$ in Cui's work. However, due to the recirculation vortex, $R_{k}$ of unit W1 (1.61\%) remains much less than Cui's work (8.32\%). This result can further illustrate that the existence of Building B improves the dilution momentum of the tracer gas in unit W1.

Finally, when the pollutant source is located in unit W4, all windward units can be affected. Comparing to the results of Cui's work, the values of $R_{k}$ beneath the source units are noticeably smaller, with $1.46 \%, 0.49 \%$ and $0.24 \%$ in present work to $5.52 \%$, $3.92 \%$ and $6.46 \%$, respectively, which reduce over $73.5 \%$. The reason for this reduction is likely to be the conflict between the dispersion and dilution momentums of the tracer gas with airflow complexity among the building blocks. With the presence of Building $\mathrm{B}$, the formation of recirculation near ground and the asymmetric vortices on both sides of windows allows more tracer gas to disperse in lateral sides.

Generally, the units on the windward side will be affected when the sources are located same side, and the room directly beneath the source unit should be included in the high-infection list in the event of a disease out-break, even though the presence of Building B reduces the possibility of pollutant inter-unit transmission to a large extent. 
The phenomenon under two upstream buildings shows dissimilar results to that with a single upstream building when the source is located windward side. As shown in Cui's work (24), more pollutants released from windward side units re-enter into those of leeward. The relatively low re-entry ratios under two upstream buildings comparing to a single one can be explained. Because of the presence of Building B, wind velocity between building A and B, shown in Fig. 10(b), is much larger than that of a single upstream building, with the combined influence of recirculation down in the windward side, causing effective pollutant dilutions, which makes the pollutants be barely transported to units in the leeward side.

Pollutants released from leeward side units show differentiable dispersion routes from windward side. On the leeward side, the near-wall flow pattern is characterized by the combination of dominant upward flow and minute recirculation near ground. Due to the airflow pattern in such circumstance, pollutants are transported upward basically, which can be observed from the summary of re-entry ratios. When the source is located in unit L4, most of the pollutant released, driven by the upward flow, easily disperse downstream and barely re-enter into other units. When the pollutants released from unit L1, L2 and L3, the tracer gas runs along the airflow patterns and re-enters into units above. The unit over the source unit has the largest value of $R_{k}$ (up to 3.17\%) comparing to others, which is most likely to get infected. $R_{k}$ of units below source unit is negligible, as well as the units in the windward side. 


\section{Under oblique wind directions $\left(\beta=+45 \&-45^{\circ}\right)$}

When the wind direction changes from normal to oblique incidence, $R_{k}$ of most units decrease significantly due to the altered airflow pattern. All the windward pollutant transmissions are considered negligible under both oblique directions. This result is easily made because of the relative large wind velocity on the windward side of target building, shown in Fig. 12(a) and (b), which is in good agreement with that under circumstance of a single upstream building (24). However, on the leeward side, recirculation zones are formed due to the pressure difference, which causes negative effect to pollutant transportation.

Under the wind direction of $+45^{\circ}(\beta=+45)$, two recirculation zones are formed on leeward side of the target building, which leads to the complexity of airflow pattern. Pollutants are transported upward basically due to the wind pattern characterized by predominant upward flow, except for the scenario of source located in unit L4. When the pollutants release from unit L1, L2 and L3, the tracer gas runs along the airflow patterns and re-enters into units above. However, when the pollutant is released from unit L4, all units below are affected non-negligibly. This is because that relative high wind velocity field and two vertices occur on the leeward, which makes the pollutant more possible to re-enter into other units. 
Under the wind direction of $-45^{\circ}(\beta=-45)$, a single recirculation zone is formed on leeward side of the target building, which leads to comparatively simple airflow pattern. Pollutants are transported upward dominantly as the wind pattern characterized by main upward flow. When the pollutants release from unit L1, L2 and L3, the tracer gas disperses with the flow patterns and re-enters into units above, while when the pollutant is released from unit L4, the pollutants directly dilute downstream and do not re-enter into other units.

\section{Inter-unit infectious risk assessment}

The infectious risk between units can be evaluated by the following equation based on the Wells-Riley model (7):

$P=1-e^{\frac{-C_{d} I q p t}{Q}}$

where $q$ is the quanta generation rate, which represents for infectious source strength built upon both the emission rate and the infectivity of the pathogen (41), I represents the number of infectors, $p$ represents the pulmonary ventilation rate of a person, $t$ is the exposure time, $Q$ is the air flow rate for each unit, and $C_{d}$ is the concentration decay coefficient, which equals to mass fraction of concentration $\left(M_{i-j}\right)$ as mentioned in section 3. When a super infector is spreading in the target building, the inter-unit infectious risk can be very high, which is similar to that of the SARS outbreak in Hong Kong (8). Assuming the infector exists in the unit, the quanta generation rate is 10,000 
quanta per hour, the pulmonary ventilation of a person is $0.6 \mathrm{~m}^{3} / \mathrm{h}$, and the exposure time is $8 h$. The inter-unit infectious risk evaluation is listed in Table 4. Colors are marked to different risk levels.

Table 4 Inter-unit infectious risk under different concentration decay coefficients.

\begin{tabular}{lll}
\hline Risk level & Concentration decay coefficient $C_{d}$ & Inter-unit infectious probability $P(\%)$ \\
\hline 6 & 1 & 100 \\
5 & 0.1 & 72.43 \\
4 & 0.01 & 12.09 \\
3 & 0.001 & 1.28 \\
2 & 0.0001 & 0.13 \\
1 & 0.00001 & $<0.13$ \\
\hline
\end{tabular}

Table 5 calculates the inter-unit infectious probability for each unit under different source locations and wind directions with color marks. It can be seen from the results that, the infectious risks are in good agreement with re-entry ratio values. The infectious risks of all units are much smaller when the wind is in oblique incidence with sources located windward side, all results are under level 3, which can be considered negligible. However, under other circumstances, the inter-unit infectious risk can reach up to $99.99 \%$. In this risk assessment, only one super infector is considered. If a second generation infection was produced in the target building, the infectious risk could be increased essentially. Thus, the risk of inter-unit dispersion should not be neglected. 
Table 5 Inter-unit infectious risks $P$ of each unit with diverse source locations under three wind directions.

\begin{tabular}{|c|c|c|c|c|c|c|c|}
\hline$P$ & $\beta=0$ & $\beta=+45^{\circ}$ & $\beta=-45^{\circ}$ & $P$ & $\beta=0$ & $\beta=+45^{\circ}$ & $\beta=-45^{\circ}$ \\
\hline W4 & $100 \%$ & $93.67 \%$ & $96.83 \%$ & W4 & $0.00 \%$ & $0.00 \%$ & $0.00 \%$ \\
\hline W3 & $58.44 \%$ & $0.00 \%$ & $0.07 \%$ & W3 & $0.00 \%$ & $0.00 \%$ & $0.00 \%$ \\
\hline W2 & $17.01 \%$ & $0.00 \%$ & $0.03 \%$ & W2 & $0.00 \%$ & $0.00 \%$ & $0.00 \%$ \\
\hline W1 & $12.66 \%$ & $0.00 \%$ & $0.03 \%$ & W1 & $0.00 \%$ & $0.00 \%$ & $0.01 \%$ \\
\hline L4 & $1.35 \%$ & $0.14 \%$ & $0.36 \%$ & $\mathrm{~L} 4$ & $100.00 \%$ & $100.00 \%$ & $100.00 \%$ \\
\hline L3 & $1.54 \%$ & $0.15 \%$ & $0.43 \%$ & L3 & $4.55 \%$ & $3.40 \%$ & $1.52 \%$ \\
\hline L2 & $1.62 \%$ & $0.15 \%$ & $0.48 \%$ & L2 & $1.17 \%$ & $3.04 \%$ & $1.35 \%$ \\
\hline L1 & $1.60 \%$ & $0.16 \%$ & $0.53 \%$ & $\mathrm{~L} 1$ & $1.04 \%$ & $2.91 \%$ & $1.28 \%$ \\
\hline W4 & $0.10 \%$ & $0.01 \%$ & $0.01 \%$ & W4 & $0.00 \%$ & $0.00 \%$ & $0.00 \%$ \\
\hline W3 & $100.00 \%$ & $93.64 \%$ & $96.22 \%$ & W3 & $0.00 \%$ & $0.00 \%$ & $0.00 \%$ \\
\hline W2 & $97.61 \%$ & $0.00 \%$ & $0.07 \%$ & W2 & $0.00 \%$ & $0.00 \%$ & $0.00 \%$ \\
\hline W1 & $60.17 \%$ & $0.00 \%$ & $0.07 \%$ & W1 & $0.00 \%$ & $0.00 \%$ & $0.00 \%$ \\
\hline L4 & $3.71 \%$ & $0.24 \%$ & $0.19 \%$ & $\mathrm{~L} 4$ & $99.99 \%$ & $54.30 \%$ & $44.71 \%$ \\
\hline L3 & $4.41 \%$ & $0.25 \%$ & $0.23 \%$ & $\mathrm{~L} 3$ & $100.00 \%$ & $100.00 \%$ & $100.00 \%$ \\
\hline L2 & $4.82 \%$ & $0.26 \%$ & $0.26 \%$ & L2 & $6.76 \%$ & $0.54 \%$ & $0.46 \%$ \\
\hline $\mathrm{L} 1$ & $4.82 \%$ & $0.27 \%$ & $0.29 \%$ & L1 & $3.72 \%$ & $0.51 \%$ & $0.42 \%$ \\
\hline W4 & $0.02 \%$ & $0.00 \%$ & $0.01 \%$ & W4 & $0.00 \%$ & $0.00 \%$ & $0.00 \%$ \\
\hline W3 & $0.09 \%$ & $0.01 \%$ & $0.03 \%$ & W3 & $0.00 \%$ & $0.00 \%$ & $0.00 \%$ \\
\hline W2 & $100.00 \%$ & $94.57 \%$ & $95.67 \%$ & W2 & $0.00 \%$ & $0.00 \%$ & $0.00 \%$ \\
\hline W1 & $72.62 \%$ & $0.00 \%$ & $0.17 \%$ & W1 & $0.00 \%$ & $0.00 \%$ & $0.00 \%$ \\
\hline L4 & $2.67 \%$ & $0.35 \%$ & $0.15 \%$ & L4 & $60.09 \%$ & $13.92 \%$ & $9.07 \%$ \\
\hline L3 & $3.21 \%$ & $0.38 \%$ & $0.18 \%$ & L3 & $91.88 \%$ & $44.55 \%$ & $37.29 \%$ \\
\hline L2 & $3.56 \%$ & $0.41 \%$ & $0.20 \%$ & $\mathrm{~L} 2$ & $100.00 \%$ & $100.00 \%$ & $100.00 \%$ \\
\hline L1 & $3.58 \%$ & $0.43 \%$ & $0.22 \%$ & $\mathrm{~L} 1$ & $4.81 \%$ & $0.44 \%$ & $0.38 \%$ \\
\hline W4 & $0.02 \%$ & $0.00 \%$ & $0.01 \%$ & W4 & $0.00 \%$ & $0.00 \%$ & $0.00 \%$ \\
\hline W3 & $0.10 \%$ & $0.00 \%$ & $0.02 \%$ & W3 & $0.00 \%$ & $0.00 \%$ & $0.00 \%$ \\
\hline W2 & $4.64 \%$ & $0.00 \%$ & $0.13 \%$ & W2 & $0.00 \%$ & $0.00 \%$ & $0.00 \%$ \\
\hline W1 & $100.00 \%$ & $95.84 \%$ & $94.64 \%$ & W1 & $0.02 \%$ & $0.00 \%$ & $0.00 \%$ \\
\hline L4 & $2.88 \%$ & $0.39 \%$ & $0.14 \%$ & L4 & $29.12 \%$ & $3.24 \%$ & $1.65 \%$ \\
\hline L3 & $3.43 \%$ & $0.44 \%$ & $0.17 \%$ & L3 & $42.43 \%$ & $3.96 \%$ & $1.87 \%$ \\
\hline L2 & $3.76 \%$ & $0.49 \%$ & $0.19 \%$ & $\mathrm{~L} 2$ & $81.75 \%$ & $18.69 \%$ & $8.12 \%$ \\
\hline L1 & $3.74 \%$ & $0.53 \%$ & $0.21 \%$ & L1 & $100.00 \%$ & $100.00 \%$ & $100.00 \%$ \\
\hline
\end{tabular}

\section{Discussion of re-entry ratio and infectious risk}

The re-entry ratio $R_{k}$ is a parameter which describes the amount of gaseous pollutants released from one unit into another. When the source is located in a specific unit, that 
the value $R_{k}$ of another unit grows higher than others represents the total pollutants of this unit is larger. While the infectious risk $P$ describes the possibility that people get infected when exposing in a specific concentration of air pollutants. The probability people get infected grows higher with the value of $P$. The re-entry ratio and infectious risk are two different parameters with separate focus points but related mathematically. By introducing air exchange rate $(A C H)$, the relation can be written as:

$P=1-e^{\frac{-I q p t}{V(A C H) i} \cdot(A C H)_{i}} \cdot R_{k}$

where $(A C H)_{i}$ is the air exchange rate of the source unit $i$ and $(A C H)_{j}$ is the re-entry unit $j$.

Some discussions can be made from the equation. Since the terms $I, q, p, t$ and $V$ are constants under a certain circumstance, the term $\frac{(A C H)_{i}}{(A C H)_{j}}$ affects the relation between $P$ and $R_{k}$ essentially. When a pollutant source location is fixed, the $(A C H)_{i}$ is a determined value, which makes $(A C H)_{j}$ a key factor in this scenario. If the re-entry unit has smaller air exchange rate under same situation, people will get infected more easily. Taking the unit W3 as an example, when the source is located in unit W4, the $R_{k}$ of unit W3 is $1.46 \%$ and the term $\frac{(A C H)_{i}}{(A C H)_{j}}$ is $467.03 \%$. However, as the term $\frac{(A C H)_{i}}{(A C H)_{j}}$ is ranging from $100 \%$ (unit $j$ has same air exchange rate with unit $i$ ) to extreme large (unit $j$ has very small air exchange rate), the inter-unit infectious rate can vary from $17.15 \%$ to $100 \%$. 
In other words, the efficiency of natural ventilation of the re-entry unit influences the infectious risk considerably. The infectious risk will increase while the ratio of air exchange rate of source unit with re-entry unit drops. Therefore, it is necessary to take re-entry ratio and infectious risk into consideration at same time when facing inter-unit dispersion problems.

\section{Conclusions}

Considering the influence of two upstream buildings, this study investigates the interunit dispersion around a multi-story building using CFD method. Re-entry ratios of infectious agents between units are analyzed and infectious risk is then assessed. Results are widely compared with previous studies that are based on an isolated building or a single upstream building. In general, this study leads to the following conclusions.

The presence of upstream buildings does not necessarily deteriorate the wind environment around its downstream building. But it changes the airflow distribution greatly and induces a relative low-speed area between upstream buildings and downstream building.

Under a normal incident wind, the addition of a second upstream building changes only slightly the ACH values of the units of its downstream building. While 
under oblique wind directions, their presence increases largely the ACH values of its downstream building.

When the wind direction is normal incidence, pollutants are dispersed mainly on the same side. The re-entry ratios from a unit to an opposite unit are very small which can be considered negligible, as well as the infectious risk. Comparing to a single upstream building, the presence of a second upstream building reduces the pollutant reentry ratio $R_{k}$ for most units when the source is located windward side, excluding a particular circumstance. While as the sources are located on the leeward side, the reentry ratios are not negligible comparing to the situation with a single upstream building, which is most likely to infect units immediately above the source units.

Under oblique wind directions, the main dispersion route of pollutants is altered from the windward side to the leeward side. The pollutants released from a windward unit disperse quickly to the outdoor wind flow and thus no obvious inter-unit dispersion occurs. However, the pollutants released from a leeward unit would transport upwards, where the units immediately above the source unit have the relatively high re-entry ratios. While the infectious risk shows the similar results.

This study reveals the inter-unit dispersion and infectious risk condition around a multi-story building when considering the presence of two upstream buildings, which extends the existing understanding of inter-unit dispersions in built environments. 
However, restricted by the computational resources, this study is still limited to a physical model with only three buildings. In addition, this study is performed in the framework of steady-state RANS modelling, which cannot reveal the transient characteristics of inter-unit dispersion. Improvements in these two aspects are expected in future studies.

\section{References}

1. Homod RZ, Sahari KSM. Energy savings by smart utilization of mechanical and natural ventilation for hybrid residential building model in passive climate. Energy and Buildings. 2013;60:310-29.

2. Schulze T, Eicker U. Controlled natural ventilation for energy efficient buildings. Energy and Buildings. 2013;56:221-32.

3. Tominaga Y, Stathopoulos T. Ten questions concerning modeling of near-field pollutant dispersion in the built environment. Building and Environment. 2016;105:390-402.

4. Santos J, Mavroidis I, Reis N, Pagel E. Experimental investigation of outdoor and indoor mean concentrations and concentration fluctuations of pollutants. Atmospheric Environment. 2011;45(36):6534-45.

5. Handbook A. ASHRAE Handbook-Fundamentals. Atlanta, GA. 2009. 
6. Yu IT, Li Y, Wong TW, Tam W, Chan AT, Lee JH, et al. Evidence of airborne transmission of the severe acute respiratory syndrome virus. New England Journal of Medicine. 2004;350(17):1731-9.

7. Riley E, Murphy G, Riley R. Airborne spread of measles in a suburban elementary school. American Journal of Epidemiology. 1978;107(5):421-32.

8. Li Y, Duan S, Yu I, Wong T. Multi - zone modeling of probable SARS virus transmission by airflow between flats in Block E, Amoy Gardens. Indoor air. 2005;15(2):96-111.

9. Niu J, Tung T. On - site quantification of re - entry ratio of ventilation exhausts in multi - family residential buildings and implications. Indoor Air. 2008;18(1):12-26.

10. Liu XP, Niu JL, Kwok KCS, Wang JH, Li BZ. Investigation of indoor air pollutant dispersion and cross-contamination around a typical high-rise residential building: Wind tunnel tests. Building and Environment. 2010;45(8):1769-78.

11. Liu X, Niu J, Kwok KC, Wang J, Li B. Local characteristics of cross-unit contamination around high-rise building due to wind effect: mean concentration and infection risk assessment. Journal of hazardous materials. 2011;192(1):160-7.

12. Wang J, Niu J, Liu X, Yu C. Assessment of pollutant dispersion in the re-entrance space of a high-rise residential building, using wind tunnel simulations. Indoor and Built Environment. 2010;19(6):638-47.

13. Mu D, Shu C, Gao N, Zhu T. Wind tunnel tests of inter-flat pollutant transmission characteristics in a rectangular multi-storey residential building, part B: Effect of source location. Building and Environment. 2017;114:281-92. 
14. Mu D, Gao N, Zhu T. Wind tunnel tests of inter-flat pollutant transmission characteristics in a rectangular multi-storey residential building, part A: Effect of wind direction. Building and Environment. 2016;108:159-70.

15. Chen Q. Ventilation performance prediction for buildings: A method overview and recent applications. Building and environment. 2009;44(4):848-58.

16. Van Hooff T, Blocken B. Coupled urban wind flow and indoor natural ventilation modelling on a high-resolution grid: A case study for the Amsterdam ArenA stadium. Environmental Modelling \& Software. 2010;25(1):51-65.

17. Ai Z, Mak C. Modeling of coupled urban wind flow and indoor air flow on a highdensity near-wall mesh: Sensitivity analyses and case study for single-sided ventilation. Environmental modelling \& software. 2014;60:57-68.

18. Gao N, Niu J, Perino M, Heiselberg P. The airborne transmission of infection between flats in high-rise residential buildings: Tracer gas simulation. Building and Environment. 2008;43(11):1805-17.

19. Liu X, Niu J, Perino M, Heiselberg P. Numerical simulation of inter-flat air crosscontamination under the condition of single-sided natural ventilation. Journal of Building Performance Simulation. 2008;1(2):133-47.

20. Ai Z, Mak C, Niu J. Numerical investigation of wind - induced airflow and interunit dispersion characteristics in multistory residential buildings. Indoor air. 2013;23(5):417-29. 
21. Ai Z, Mak C. A study of interunit dispersion around multistory buildings with single-sided ventilation under different wind directions. Atmospheric Environment. 2014;88:1-13.

22. Ai Z, Mak C. Analysis of fluctuating characteristics of wind-induced airflow through a single opening using LES modeling and the tracer gas technique. Building and environment. 2014;80:249-58.

23. Ai Z, Mak C. Large eddy simulation of wind - induced interunit dispersion around multistory buildings. Indoor air. 2016;26(2):259-73.

24. Cui DJ, Mak CM, Kwok KCS, Ai ZT. CFD simulation of the effect of an upstream building on the inter-unit dispersion in a multi-story building in two wind directions. Journal of Wind Engineering and Industrial Aerodynamics. 2016;150:31-41.

25. Launder BE, Spalding D. The numerical computation of turbulent flows. Computer methods in applied mechanics and engineering. 1974;3(2):269-89.

26. Tsuchiya M, Murakami S, Mochida A, Kondo K, Ishida Y. Development of a new $\mathrm{k}-\varepsilon$ model for flow and pressure fields around bluff body. Journal of Wind Engineering and Industrial Aerodynamics. 1997;67:169-82.

27. Yakhot V, Orszag SA. Renormalization group analysis of turbulence. I. Basic theory. Journal of scientific computing. 1986;1(1):3-51.

28. Stathopoulos T. Computational wind engineering: Past achievements and future challenges. Journal of Wind Engineering and Industrial Aerodynamics. 1997;67:509-32. 
29. Yakhot V, Orszag S, Thangam S, Gatski T, Speziale C. Development of turbulence models for shear flows by a double expansion technique. Physics of Fluids A: Fluid Dynamics (1989-1993). 1992;4(7):1510-20.

30. Leitl B, Schatzmann M. Compilation of experimental data for validation purposes. CEDVAL (Meteorology Institute, Hamburg University) URL http://www mi unihamburg de/cedval. 1998.

31. Gorlé C, Van Beeck J, Rambaud P, Van Tendeloo G. CFD modelling of small particle dispersion: the influence of the turbulence kinetic energy in the atmospheric boundary layer. Atmospheric Environment. 2009;43(3):673-81.

32. Richard P, Hoxey R. Appropriate boundary conditions for computational wind engineering models using the k-e turbulence model. J Wind Eng Ind Aerodyn. 1993;46:145-53.

33. T. AZ, M. MC. CFD simulation of flow and dispersion around an isolated building: Effect of inhomogeneous ABL and near-wall treatment. Atmospheric Environment. 2013;77:568-78.

34. Fluent AF. 13.0 Theory Guide, Turbulence. ANSYS Inc, Canonsburg, PA. 2010.

35. Tominaga Y, Stathopoulos T. Turbulent Schmidt numbers for CFD analysis with various types of flowfield. Atmospheric Environment. 2007;41(37):8091-9.

36. Blocken B, Stathopoulos T, Saathoff P, Wang X. Numerical evaluation of pollutant dispersion in the built environment: comparisons between models and experiments. Journal of Wind Engineering and Industrial Aerodynamics. 2008;96(10):1817-31. 
37. Ai Z, Mak C. Potential use of reduced-scale models in CFD simulations to save numerical resources: Theoretical analysis and case study of flow around an isolated building. Journal of wind engineering and industrial aerodynamics. 2014;134:25-9.

38. Franke J. Best practice guideline for the CFD simulation of flows in the urban environment: Meteorological Inst.; 2007.

39. Meroney R. Wind tunnel and numerical simulation of pollution dispersion: a hybrid approach. Paper for Invited Lecture at the Croucher Advanced Study Institute, Hong Kong University of Science and Technology. 2004:6-10.

40. Oke T. Boundary layer climates, 372. Methuen, New York. 1978.

41. To S, Nam G. Risk assessment of infectious respiratory disease transmission in indoor environments 2010. 